\title{
Correction to: Posttraumatic acute choroidopathy
}

\author{
Özlem Dikmetas · Annegret Abaza • Faik Gelisken
}

Published online: 26 July 2018

(C) Springer Nature B.V. 2018

\section{Correction to: Int Ophthalmol}

https://doi.org/10.1007/s10792-017-0810-1

In the original publication, Figure 2 was published incorrectly. The correct version is given in this correction (Fig. 2).

A1 The original article can be found online at

A2 https://doi.org/10.1007/s10792-017-0810-1.

A3 Ö. Dikmetas

A4 Department of Ophthalmology, University of Kastamonu,

A5 Kastamonu, Turkey

A6 A. Abaza - F. Gelisken

A7 Department of Ophthalmology, Eberhard-Karls

A8 University, Tuebingen, Germany

A9 F. Gelisken ( $\square)$

A10 Universitäts-Augenklinik, Elfriede-Aulhorn-Str. 7,

A11 72076 Tuebingen, Germany

A12 e-mail: faik.gelisken@med.uni-tuebingen.de 


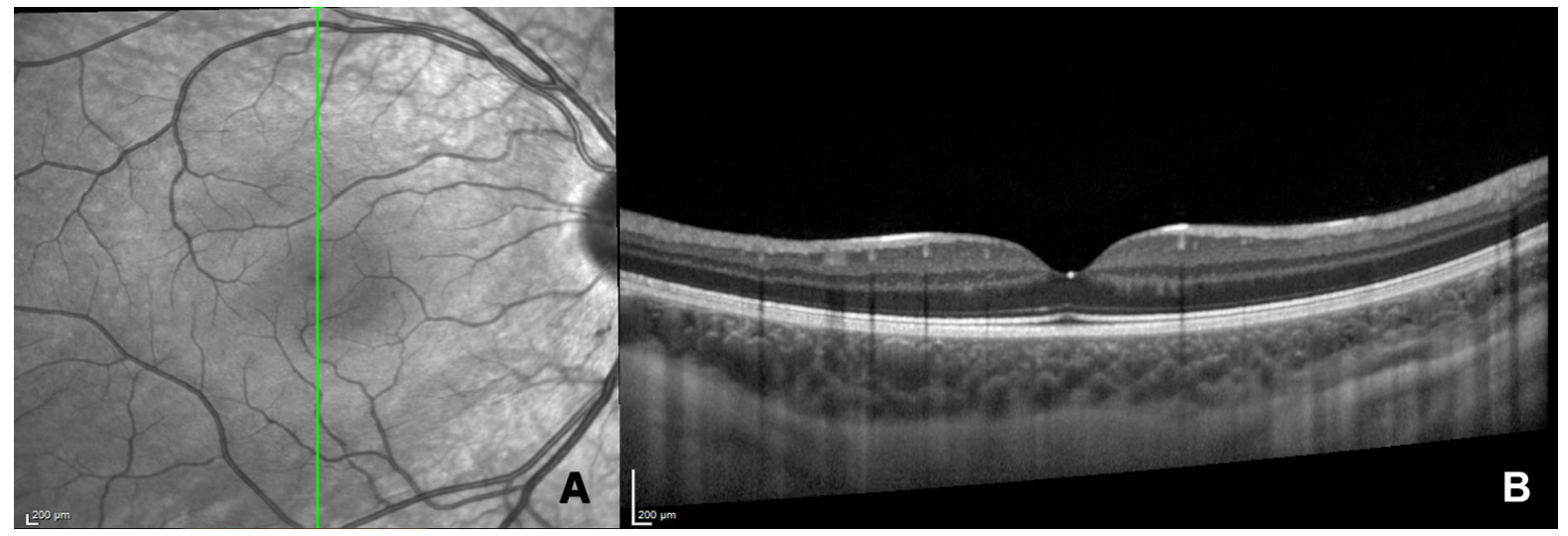

Fig. 2 a Infrared image of the right eye 6 months later. b OCT-EDI revealed a normal choroidal thickness of $277 \mu \mathrm{m}$. No separation of the Haller's layer was seen 